\title{
Coordinated management of coastal hazard awareness and preparedness in the USVI
}

\author{
R. A. Watlington ${ }^{1}$, E. Lewis ${ }^{2}$, and D. Drost ${ }^{3}$ \\ ${ }^{1}$ Caribbean Coastal Ocean Observing System, St. Thomas, US Virgin Islands \\ ${ }^{2}$ Virgin Islands Territorial Emergency Management Agency, St. Croix, US Virgin Islands \\ ${ }^{3}$ University of the Virgin Islands, St. Thomas, US Virgin Islands
}

Correspondence to: R. A. Watlington (rawatlington@gmail.com)

Received: 1 August 2013 - Revised: 1 April 2014 - Accepted: 2 April 2014 - Published: 30 April 2014

\begin{abstract}
As far back as history has been written in the islands today known as the US Virgin Islands (USVI), residents have had to endure and survive costly and deadly onslaughts from tropical storms such as the 1867 San Narciso Hurricane, Hurricane Hugo and Hurricane Marilyn. Keenly alerted by recent tragic events in the Indian Ocean in 2004, in Haiti in 2010 and in Japan in 2011, the USVI was reminded that it had suffered its greatest tsunami impact in a well-documented event that had followed the 1867 hurricane by fewer than three weeks. To address their community's continual vulnerability to coastal hazards, USVI emergency managers, scientists and educators, assisted by national and regional disaster management agencies and warning programs, have engaged programs for understanding, anticipating and mitigating these hazards. This paper focuses on how three public-serving institutions, the Virgin Islands Territorial Emergency Management Agency (VITEMA), the University of the Virgin Islands and the Caribbean Ocean Observing System have responded to the community's need for improved preparedness through programs of physical preparation, planning, research, observations, education and outreach. This report reviews some of the approaches and activities employed in the USVI in the hope of sharing their benefits with similarly vulnerable coastal communities.
\end{abstract}

\section{Introduction}

As a result of its location, the United States Virgin Islands (USVI), an island community of approximately 106000 citizens, is at-risk for impacts from several coastal hazards. The natural disturbances of 1989 through 1999 created both demand and opportunity for advancing preparedness and awareness in the face of coastal natural hazards in the USVI. This was the period when Hurricanes Marilyn, Lenny and other storms destroyed and terrorized the community and when also Montserrat's Soufriere Hills volcano returned to activity after more than 300 years (Wallace, 2006). After decades relatively unscathed, many of the communities of the Caribbean experienced a succession of direct hits and near misses by severe tropical storms. At the same time, even at a safe distance from significant direct fallout, the people of the northeast Caribbean were provided with worrisome front row seats to the hazard that the newly awakened volcano represents.

\section{USVI demographic and geologic setting}

The US Virgin Islands is an unincorporated territory of the USA with limited self-rule. The main inhabited islands are St. Croix, St. John, St. Thomas and Water Island. These islands and surrounding cays and islets encompass $346.4 \mathrm{~km}^{2}$ $\left(133.6 \mathrm{mi}^{2}\right)$. According to the 2012 US census, approximately 105,275 people reside in the Virgin Islands (CIA, 2014). With tourism the main industry, the islands accommodate more than 2 million people who visit annually to enjoy the warm climate, clear waters, white sandy beaches and the culture. Located near the northeastern margin of the Caribbean tectonic plate, at the easternmost limit of the Greater Antilles Island chain, the islands lie approximately $150 \mathrm{~km}$ south of the Puerto Rico Trench and are bounded by the Anegada Passage to the east and by the Muertos Trench and Venezuela Basin to the south. These and other seismically active features as well as several active faults contribute to the region's vulnerability to earthquakes and tsunamis 
(Nealon and Dillon, 2001). They are rated by the 1997 Uniform Building Code as a Seismic Zone 4 (IVI International, 2014).

\section{Major coastal hazards impacting the USVI}

Everyone living or visiting the USVI, tourists along with the local population, is susceptible to the natural hazards that occasionally impact the Territory - Atlantic tropical storms, particularly during the hurricane season, flooding, earthquakes in this seismically active region, and tsunamis.

\subsection{Tropical storms}

As far back as records have been kept, the Northeastern Caribbean has compiled narratives and damage reports about destructive, sometimes very deadly, tropical storms. Before he migrated to the US to eventually become one of its founding fathers - Chief of Staff to General George Washington, member of the Continental Congress, Secretary of the Treasury, and founder of the Federalist Party - Alexander Hamilton lived in St. Croix and witnessed the destructive and deadly hurricane of 1772 . In a letter penned to his father and later published he described the experience and impacts of the storm, “... A great part of the buildings throughout the Island are levelled to the ground - almost all the rest very much shattered - several persons killed and numbers utterly ruined - whole families running about the streets unknowing where to find a place of shelter - the sick exposed to the keenness of water and air - without a bed to lie upon—or a dry covering to their bodies - our harbour is entirely bare ..." (Hamilton, 1772).

USVI communities have long recognized tropical storms to be their primary natural hazard threat. As shown in Fig. 1, the USVI is located in the area designated by the National Oceanic and Atmospheric Administration's Climate Prediction Center as the Main Development Region (MDR) for Atlantic tropical storms that originate off the West African coast.

For example in 1713, 1772 and 1819, 1837, 1867 and 1916, severe hurricanes impacted these islands, which until 1917 were the Danish West Indies (Dookhan, 1974). The most fatal of all occurred on 29 October 1867 and resulted in the loss of more than 500 lives with massive destruction to residential property, infrastructure and the vessels of several nations (vanHousel, 1878). Significantly damaging tropical storm events have continued to the present, often interspersed with long periods of quiet. After the Danish West Indies became the US Virgin Islands, the years 1924, 1928, and 1932 brought more destructive storms. Among modernnamed storms, Tropical Storm Betsy (1956) and Hurricane Donna (1960) threatened the communities and damaged reefs but did not devastate the islands. In 1984 Klaus surprised the islands by causing more wind damage and flooding

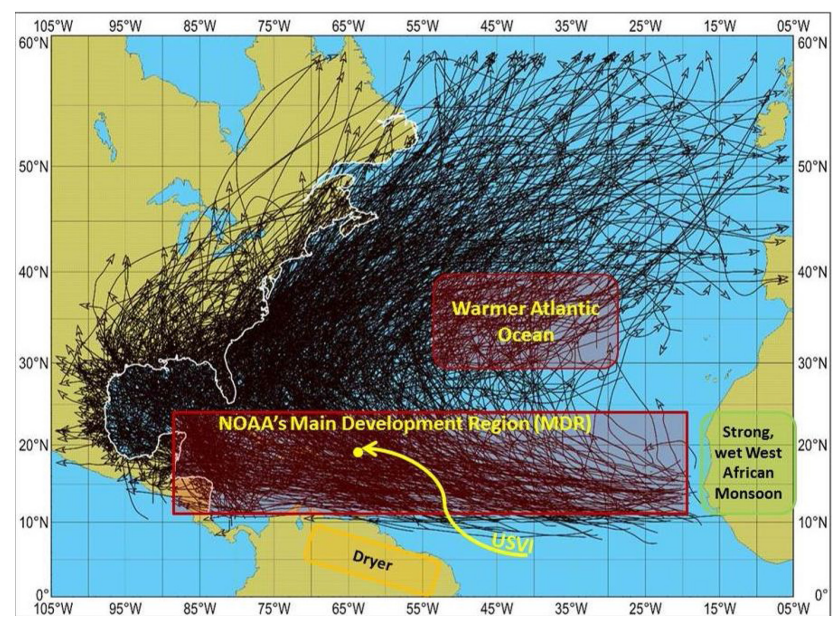

Fig. 1. MDR and hurricane tracks 1851-2004. The arrow indicates the location of the USVI within the sector designated as the Main Development Region (MDR) for tropical storm activity since 1995 in the months August through October (synthesis of NOAA graphics, after Climate Prediction Center, 2013).

than was expected from a tropical storm, although it was soon to become a hurricane.

The havoc that Hurricane Gilbert wreaked in Jamaica in 1988 after passing south of the Virgin Islands captured the attention of its people and, in retrospect, is seen as a preview of the stunning impact that Hurricane Hugo would make locally the next year. Hugo took lives, severely damaged USVI infrastructure and had a negative impact on its economy, particularly on St. Croix. The Earthquake Engineering Research Institute (EERI) reported that, “... losses of $\$ 1.5$ billion (mostly concentrated on St. Croix) included damage or destruction of 95 percent of the buildings and 90 percent of the power supply system .... Nearly every public building on the island, including the hospital, schools, housing projects and shelters, sustained major damage or were destroyed" (FEMA, 2008; EERI, 2014). The St. Croix Foundation, for example, committed itself in 1990 to assist St. Croix, “... after Hurricane Hugo destroyed St. Croix's socioeconomic fabric in 1989" (St. Croix Foundation, 2014).

In 1995 Hurricane Marilyn, rivaling Hurricane Hugo, was the most destructive of a series of hurricanes and tropical storms that would hit or graze the islands throughout that decade and further weaken the slowly recovering economy. As shown in Fig. 2, employment, as a credible measure of economic and social health, reflected the reality of the negative impacts of hurricanes.

Impact of storms on the USVI economy is further illustrated by examining General Fund Revenues for a period of storm activity as in Fig. 3. As the USVI Department of Finance reported, "Revenues in 1996 were down approximately 8.1 percent to $\$ 347$ million (mostly due to a drop in revenues after Hurricanes Marilyn and Bertha) ..." (Department of Finance, Government of the US Virgin Islands). 


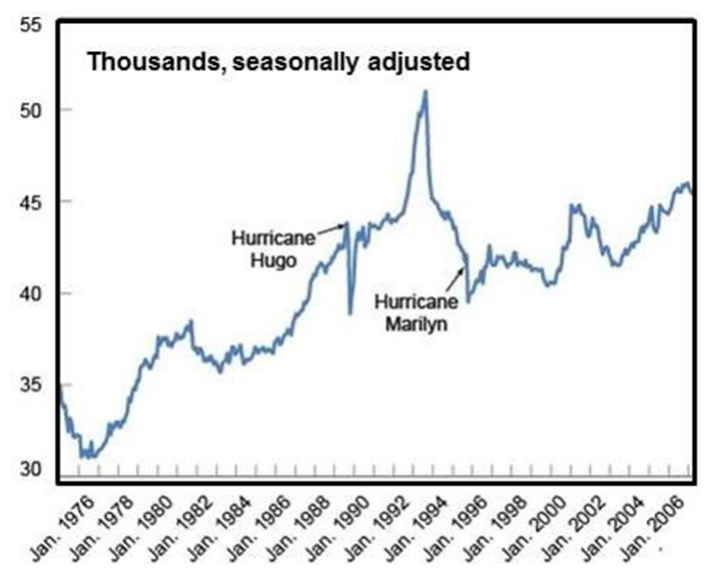

Fig. 2. Hurricane Impacts on USVI Employment Source: US Bureau of Labor Statistics, Haver Analytics (after Bram and Hastings, 2013).

By the time the 1999 Hurricane Lenny had spread its disruption along its unusual path from west to east, scientific explanations of natural cycles of hurricane intensification only heightened the public's anxiety about hazards to which their islands could be susceptible (Goldenberg et al., 2001; Climate Prediction Center, 2013).

\subsection{Tsunamis}

Anxiety about the threat of tsunamis may have started in the USVI in 1995 when the general public heard suggestions that collapse of the flanks of Montserrat's volcano could generate destructive waves or that the submarine volcano in the southeastern Caribbean, Kick-'em-Jenny, could erupt with enough energy to send tsunamis across the Caribbean. But eventually concern about these possibilities led to the recovery from forgotten history of the well-documented earthquake and tsunami of 1867 when the USVI were ruled by Denmark and known as the Danish West Indies.

At 16:50 UTC on 18 November 1867, triggered by abrupt and energetic rupture on the floor of the Virgin Islands Basin, an earthquake with magnitude between 7.2 and 7.5 (Barkan and ten Brink, 2010; Zahibo, et al., 2003), generated tsunami waves that began inundating the shoreline communities of the surrounding islands - Frederiksted, Charlotte Amalie, Christiansted, Road Town - within approximately $10 \mathrm{~min}$. Waves of $7 \mathrm{~m}$ were recorded around the basin but wave heights as great as $10 \mathrm{~m}$ were recorded at two locations in Guadeloupe (Zahibo et al., 2003). Tsunami waves propagated cross the Caribbean to inflict coastal damage as far away as Grenada. By the time the waves had abated, coastal devastation of infrastructure, homes and marine industries was extensive. Commerce was damaged, yet the loss of life was surprisingly low with fewer than 30 people killed in the Danish West Indies by both earthquake and tsunami and only a small numbers of fatalities occurred in the British Virgin

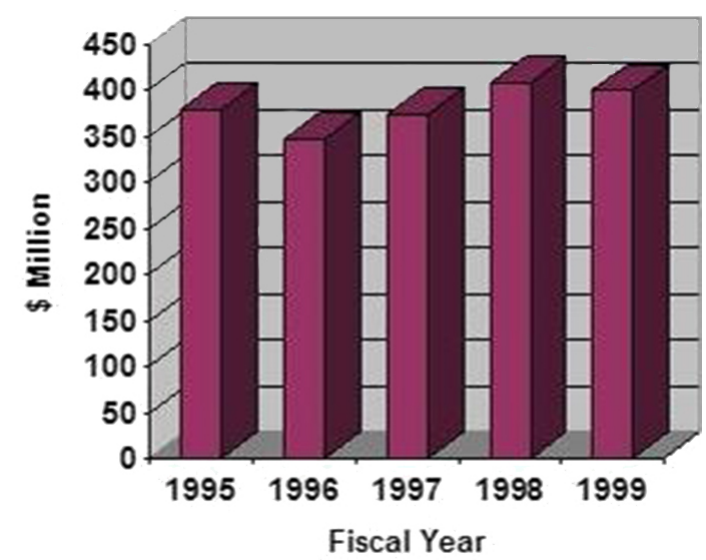

Fig. 3. General Fund Revenues, FY 1995-99, Government of the US Virgin Islands. "Tax and non-tax revenues, not including contributions" (Department of Finance, Government of the US Virgin Islands, 1999).

Islands and eastern Puerto Rico. A survey of the islands' topography reveals an abundance of promontories overlooking populated at-risk coastal areas. It is commonly conjectured that the proximity of these hills made escape routes accessible. Low mortality in the 1867 catastrophe may also reflect the relatively small population at the time (Dookhan, 1984). Further, at mid-afternoon, workers in the dominant industry of the period would be found inland and upland on farms and plantations.

\subsection{Vulnerability today}

The prospect of a similar tsunami striking these same shores today is frightening and is much discussed. In 1867 the population of the Danish West Indies was approximately 37000 (Dookhan, 1974), that number has now almost tripled (CIA, 2014). Instead of inland, upland on plantations and farms, most of today's industries are headquartered on the coast. USVI tourism, the main industry, is largely focused on coastal activity. On an average day in tourism high season, as many as six cruise ships, each bearing several thousand passengers and crew, may rest in the Charlotte Amalie harbor. Even on St. Croix, where a more extensive interior provides inland recreational and educational activities for visitors, marine and coastal activities still comprise the substance of accommodations for tourists. Much of the Islands' infrastructure is found on the coast as well (Watlington, 2006). The modified Google Earth satellite view in Fig. 4 reveals cruise ship docks, container and shipping ports, airports, gift shops and tourism recreation facilities on St. Thomas - all within coastal areas known to have been inundated by the 1867 tsunami. In addition, many government offices, some schools and some public housing are also found at vulnerable elevations. Storm surge modeling predicts inundation depths 


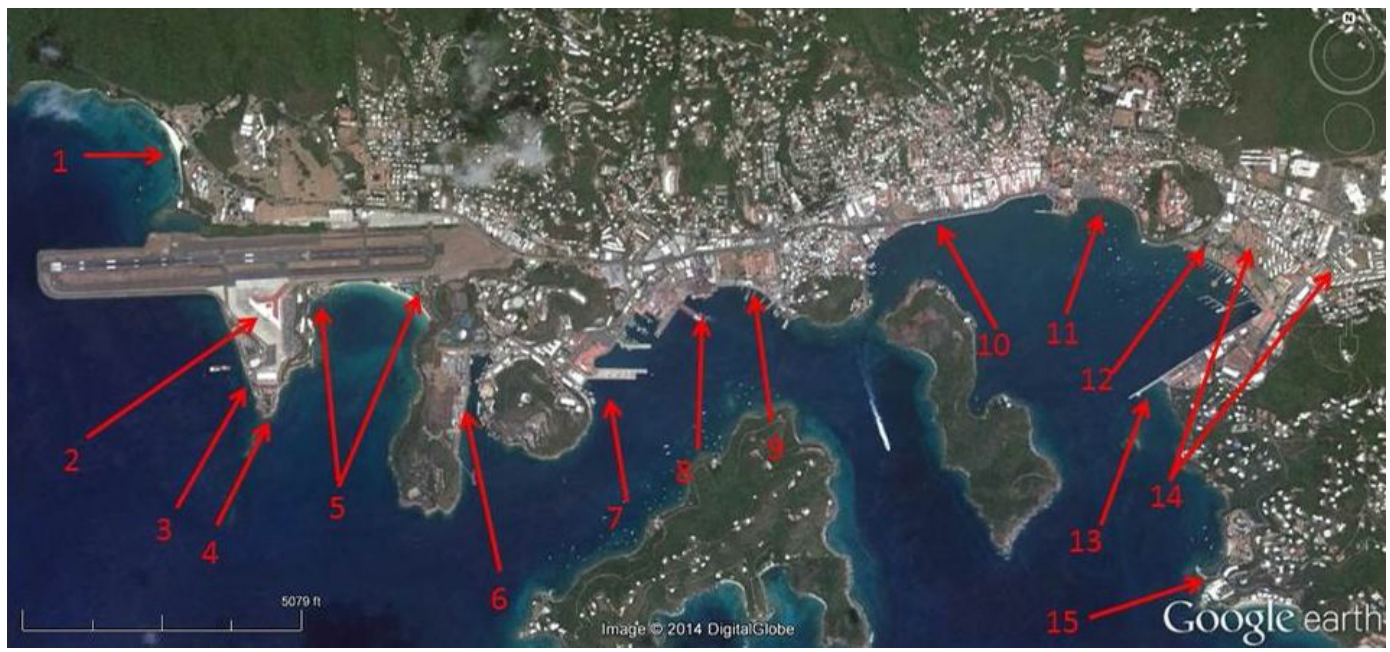

Fig. 4. At-risk sites in and near Charlotte Amalie, St. Thomas, USVI. (1) Shoreline university buildings, (2) airport, (3) airplane fuel storage, (4) sewage treatment plant, (5) three shoreline hotels, (6) electricity and desalination plants with storage tanks, (7) 3-berth dock that accommodates the world's largest cruise ships, (8) marina and container port, (9) school for > 900 students, (10) downtown shopping and historic district, (11) courts, police station and jail, (12) 85-unit senior citizens home, (13) cruise ship dock and upscale marina, (14) two public housing projects with 417 dwellings and (15) hotel/resort.

between 0.10 and $2.29 \mathrm{~m}$ in this zone during a category 5 hurricane (Benitez and Mercado, 2014).

\subsection{Community responses and expectations}

The coastal catastrophes that occurred in USVI over the past three decades along with the vulnerabilities that have been revealed resulted in many constructive responses from various levels of the society. While acceptance of these vulnerabilities may have weakened many individuals' self-confidence in their ability to persevere in the face of severe natural events and diminished confidence in government leaders and emergency managers, appropriate responses to these threats by individuals and government alike became evident even as new tropical storms threatened.

A survey conducted after Hurricane Georges in 1998 identified behaviors in private citizens consistent with a commitment to secure safety during cataclysmic events. Eighty percent of the study's participants knew how to appreciate the threat that an approaching hurricane would represent for three days or more in advance and took warnings seriously. Further eighty-one percent indicated that they were well prepared with supplies before the hurricane (Sattler et al., 2000).

The US Department of Homeland Security (DHS) was able to assist the Government of the Virgin Islands in improving building codes in order, "... to attempt to accommodate the hurricanes or earthquakes that are now known to be possible with citizens being encouraged to build their houses with consideration given to storm-resistant designs and measures and to comply more carefully with these codes". For example, the new code requires hurricane resistant measures such as anchoring systems, hurricane clips and shutters
(DHS, 2014). DHS assisted other mitigation projects including, “... the strengthening of infrastructure facilities and a massive public education outreach to contractors and owners about proper construction practices and other mitigation strategies". Then after Hurricane Marilyn, the Governor's Home Protection Roofing Program was established to repair damaged roofs and design them to withstand a Category 2 storm (DHS, 2014).

In spite of these efforts, preparedness to face coastal hazards while at the same time considering the region's seismic portent requires even more of the Government, more of the individual, and more acceptance of responsibility by other sectors of the community. This expectation provides an opportunity for organizations with special capabilities to help meet the challenge of awareness and preparedness for coastal hazards.

\section{Coordinated management of risk and responsibility for preparedness}

\subsection{Mission and activities of the Virgin Islands Territorial Emergency Management Agency}

Official responsibility and authority for providing the people of the US Virgin Islands with disaster preparedness and warning is vested in the Virgin Islands Territorial Emergency Management Agency (VITEMA), which was created in 1985 with the overarching mission of saving lives and property. At that time, and even more so after the onslaughts of Hugo, Marilyn and the others, the Territory's preparedness effort was hurricane-centric, focusing on readiness for the Atlantic 
hurricane season. This was but one of the challenges the new office faced. Twenty-three years later, to address inefficiencies in the emergency management, the Governor of the US Virgin Islands, John P. de Jongh Jr. made improving the system a top priority of his administration and an all-hazards approach was adopted.

\subsubsection{Restructuring}

Following a national trend, Governor deJongh, enacted the Emergency Management Act of 2009 which elevated VITEMA to stand-alone, cabinet level with jurisdiction over the previously separated functions such as the 911 system, which was under the VI Police Department, the VI Office of Homeland Security, which was under the Office of the Adjutant General, and the Public Assistance Unit, which was under the Office of Management and Budget. The overhaul of 2009-2010 realigned VITEMA's personnel and mission to mirror the US Government standards, established by the Federal Emergency Management Agency (FEMA) of the US Department of Homeland Security. Its staff of approximately 25 employees Territory-wide grew to approximately $100 \mathrm{em}-$ ployees in five divisions.

Early accomplishments included the modernization of the Emergency Operations Centers (EOCs) and of the 911 system, on duty $24 \mathrm{~h}$ daily every day, the creation of a Virgin Islands Fusion Center and the opening of the campaign to achieve recognition as TsunamiReady ${ }^{\mathrm{TM}}$ (i.e. "Tsunami Ready") by the US National Weather Service (NWS).

The Fusion Center is a unit of VITEMA's Office of Homeland Security established by the Governor's Executive Order to improve intelligence gathering and sharing among public safety and public service agencies. During 2011, the Fusion Center offered the highly technical courses for local and federal law enforcement agencies and emergency response personnel and private sector security organizations and assists these facilities by identifying security weaknesses and suggesting corrective actions.

VITEMA created separate and distinct divisions with clear functional missions, focusing more comprehensively and strategically on readiness for all-hazards. The reorganized agency began expanding its vision to readiness for allhazards, natural and anthropogenic, including earthquakes, tsunamis, tropical storms and acts of terrorism. Throughout VITEMA's transformation, critical steps were taken to make the vision of all-hazards readiness an achievable goal, looking at existing practices in managing incidents, strengths and gaps in our existing strategic plans, and at the capability of the homeland security office (Lewis, 2014). This analysis resulted in strengthened emergency response and recovery capabilities, improved planning, communications, coordination and cooperation, and renewed internal organizational strength.

Also a result of its reorganization, VITEMA achieved compliance with the US National Incident Management
System (NIMS), which was developed by the Department of Homeland Security for the management of incidents. This system allows various levels of government, nongovernmental organizations, and the private sector to work seamlessly to respond to and recover from disasters, regardless of the cause, size, location, or complexity. Today FEMA and other US government agencies can and have seamlessly integrated and co-located with VITEMA, particularly for storm response.

\subsubsection{Towards TsunamiReady recognition}

With this reorganization, VITEMA expanded its vision of preparedness and set out to achieve TsunamiReady status in 2013 and set out to meet the criteria (NWS, 2014) with the following actions:

- advancing broad education and participation of the citizenry with the convening of Territorial tsunami working groups pinpointed communities considered most at-risk;

- developing an updated tsunami response plan;

- deploying on all-hazards warning siren system;

- identifying evacuation routes and developed evacuation maps; and

- purchasing and deploying tsunami signage.

\subsubsection{Territorial Tsunami Working Groups}

With two new state-of-the-art 911 communications centers and modernized emergency operations centers, becoming a "Tsunami Ready community came more sharply into view. In 2009, Territorial Tsunami Working Groups (TTWG) were formed to pinpoint USVI communities most at-risk in the event of a tsunami. The TTWG, comprised of representatives of the private and public sector, worked together to develop a decision matrix for choosing the initial communities in the Territory in which to pursue tsunami-readiness. The decision matrix included each site's population density, location and elevation, proximity to safe areas and feasibility for tsunami readiness at the present time. For initial TsunamiReady focus, the process identified the town of Charlotte Amalie and Magens Bay Beach in St. Thomas, the town of Frederiksted on St. Croix and Cruz Bay on St. John. With the sites identified, representatives of VITEMA and the Department of Public Works identified areas for placement of tsunami hazard zone and evacuation route signs. To close the gap on timely public notification for this type of event, VITEMA purchased an all hazards siren system to be installed at those sites identified as most at-risk. Finally, we began to look at developing a comprehensive strategic tsunami response plan. 


\subsubsection{A tsunami plan}

In December of 2010, VITEMA hired Witt Associates, a public safety and crisis management consulting firm, to help establish a tsunami response plan. The final draft of the Tsunami Incident Annex is intended to be incorporated as an addendum to the Territorial Emergency Operations Plan. No such plan existed prior to this and its completion is a significant milestone in VITEMA's planning efforts. The Tsunami Incident Annex establishes guidelines for VITEMA and other primary emergency response agencies to utilize in an effort to minimize the potential for loss of life from a tsunami incident. It provides guidance on how emergency managers can provide timely, accurate, reliable, and effective tsunami information and support to at-risk populations, government agencies, schools and other organizations and institutions within the Territory on a timely basis. As part of the development process, VITEMA and Witt Associates' planners, spent several weeks meeting and gathering pertinent data from various local government agencies, key infrastructure officials, field experts, and the University of the Virgin Islands' Conservation Data Center. Approved in 2011, the final draft of the Tsunami Incident Annex has been incorporated as an addendum to the Territorial Emergency Operations Plan (VITEMA, 2011).

VITEMA also conducted the first tsunami-specific preparedness exercise ever held in the Virgin Islands in October 2011. The exercise provided an opportunity for first responders, local and federal agencies and the private sector to evaluate procedures for a structured and coordinated response to a tsunami, using the newly-created Tsunami Incident Annex.

\subsubsection{Signs and sirens}

In pursuit of improved public safety through TsunamiReady preparations, VITEMA has installed 100 tsunami hazard zone and evacuation route signs across the Territory. In December 2010 VITEMA purchased a siren warning system to address the public notification gap for no-notice type events such as tsunami. Phase 1 of the system was activated in the summer 2011 as ten sirens were installed across the Territory. Phase II of the siren system installation will include an additional six sites on St. Croix and five on St. Thomas, for a total of 21 sirens Territory-wide.

\subsubsection{Tsunami evacuation maps}

In December of 2013, the Governor of the US Virgin Islands, the Honorable John P. deJongh, formally accepted the first publication of Tsunami Evacuation maps for St. Croix, St. John and St. Thomas. VITEMA completed the development and publication of these important contributions to Tsunami Readiness with the assistance of FEMA, NOAA, and the Caribbean Tsunami Warning Program. The map for the island of St. John is shown in Fig. 5. The map reflects the convention of demarking the evacuation zone at the $25 \mathrm{~m}$ ( 82 foot) topographical contour. Historical storm surge data, storm surge modeling and records of observations of the tsunami of 1867 were used to establish a reasonable zone of safety. To insure against persons taking intuitive but illadvised paths to safety, arrows are used to show the recommended directions of flight from the evacuation zone. The map for Water Island is under development. Along with the St. John map of Fig. 5, maps for St. Croix and St. Thomas are available on VITEMA's web page (VITEMA, 2013).

\subsubsection{Fostering public awareness}

A robust media campaign that has already started, involving youth and the private sector, will provide the general public with tsunami awareness, education and plans for mitigation, response and recovery. Attractive public service announcements have been developed, taped and publicized. In addition with FEMA's support, VITEMA is carrying out a major commitment to provide tsunami awareness to all levels of employees of government, hospitals and public-serving institutions in day-long sessions conducted by the University of Hawaii's National Disaster Preparedness Training Center (NDPTC). The FEMA-certified course is organized into the following modules:

- science and hazard assessment,

- tsunami detection and warning processes,

- preparedness and response,

- exercise scenarios,

- tsunami mitigation,

(NDPTC, 2014).

By end of the end of 2013 hundreds of public and private sector employees had been reached.

\section{The University of the Virgin Islands responds}

The tripartite mission of the University of the Virgin Islands (UVI) mandates education, research and community service. From 1989 (Hurricane Hugo) to the present UVI has deliberately developed itself into a respected source of natural hazard information for the community. UVI's clients include local emergency managers, decision makers, other educators and elected officials needing more background in order to discharge their responsibilities with respect to frequent tropical storms, the ominous presence of a newly active volcano on a neighboring island, and the growing awareness of earthquake and tsunami vulnerability.

UVI is a public land-grant institution that was founded in 1962 with campuses on St. Croix and on St. Thomas and an academic center on St. John, where it also maintains the 


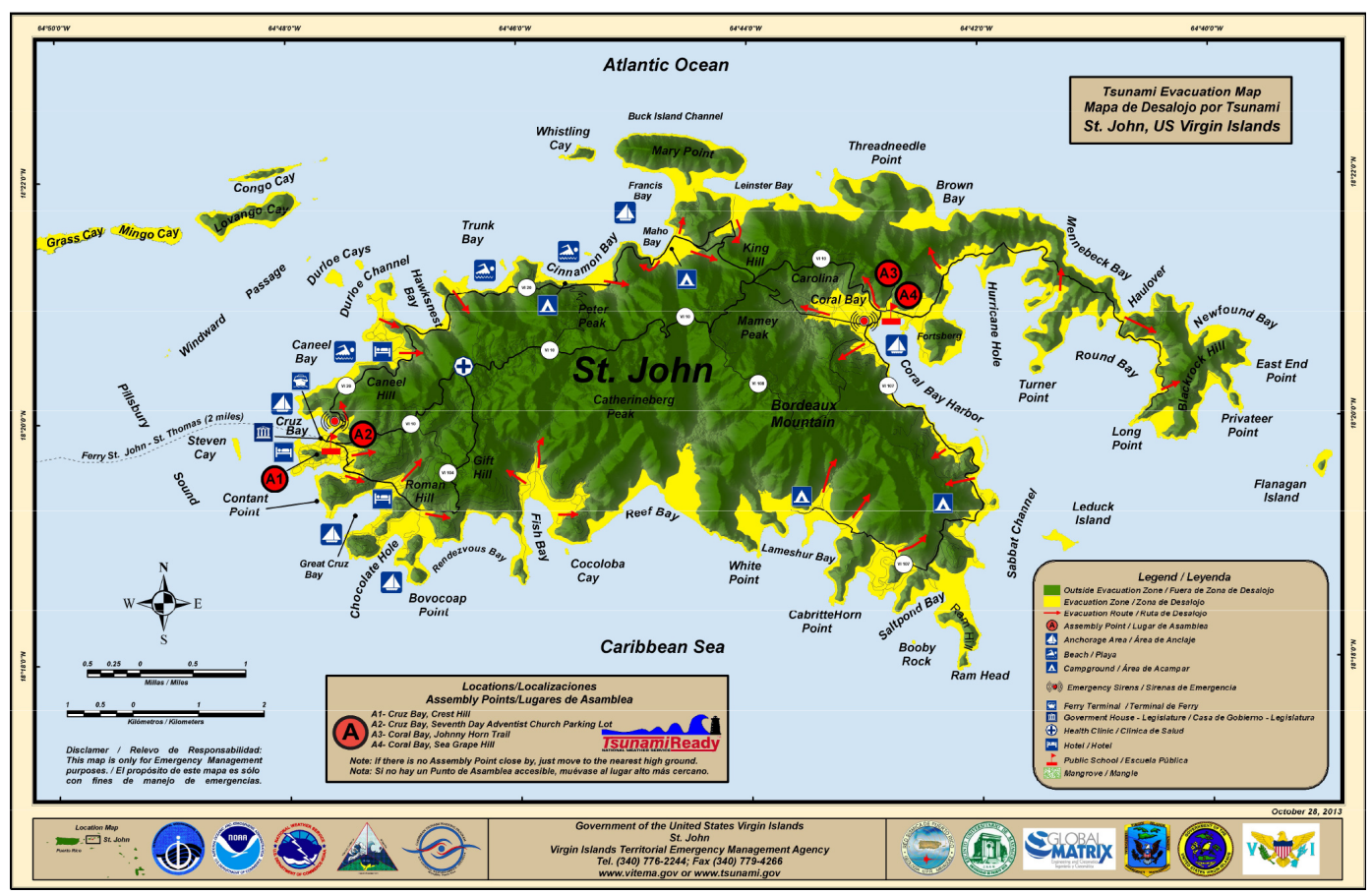

Fig. 5. Tsunami evacuation map for St. John, USVI. The yellow portions are land areas that are below $25 \mathrm{~m}$ ( $82 \mathrm{feet}$ ) elevation and are considered zones to be evacuated (VITEMA, 2013).

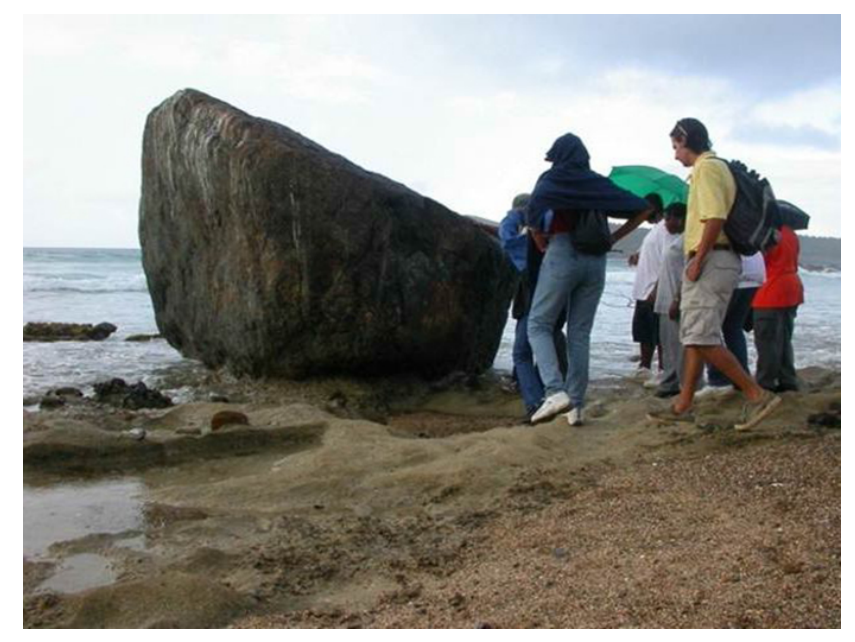

Fig. 6. Science 100 students examining tsunami deposits. This boulder is hypothesized to have been deposited on the St. Thomas north shore by a tsunami (P. Mills photo, 2005).

Virgin Islands Environmental Resource Center. Its admission policy is basically open-admissions. UVI offers bachelors and master's degrees in a wide range of disciplines. All sectors of the University participate in one or more of these services to the community. Examples of services UVI has provided in support of natural hazard awareness, preparedness and mitigation are listed below:
- the first assembly of global tsunami experts to address the Caribbean region, convened on behalf of the National Oceanic and Atmospheric Administration (NOAA) and the Intergovernmental Oceanographic Commission;

- initiating and assisting NOAA in conducting bathymetric surveys of the submarine volcano known as "Kick-'em-Jenny" to evaluate its potential to erupt and generate a tsunami that could reach the USVI in less than $90 \mathrm{~min}$ (Smith and Shepard, 1994);

- assistance to resource managers, government scientists and environmental groups in post-disaster recovery of storm-damaged mangrove stands, coral reefs and sea grass beds and intensified efforts in educating decision makers as well as the general public about the value of such natural resources and their roles in defending against storm surge, tsunami, wind damage;

- support of the Puerto Rico Seismic Network in upgrading seismic stations and in deploying GPS instruments for detecting detailed motion of the Caribbean tectonic plate;

- tsunami awareness training (provided pro bono) for emergency managers, social organizations, school teachers and public facilities such as beaches;

- the pioneering of natural hazard education with the acclaimed Science 100, as illustrated in Fig. 6. 


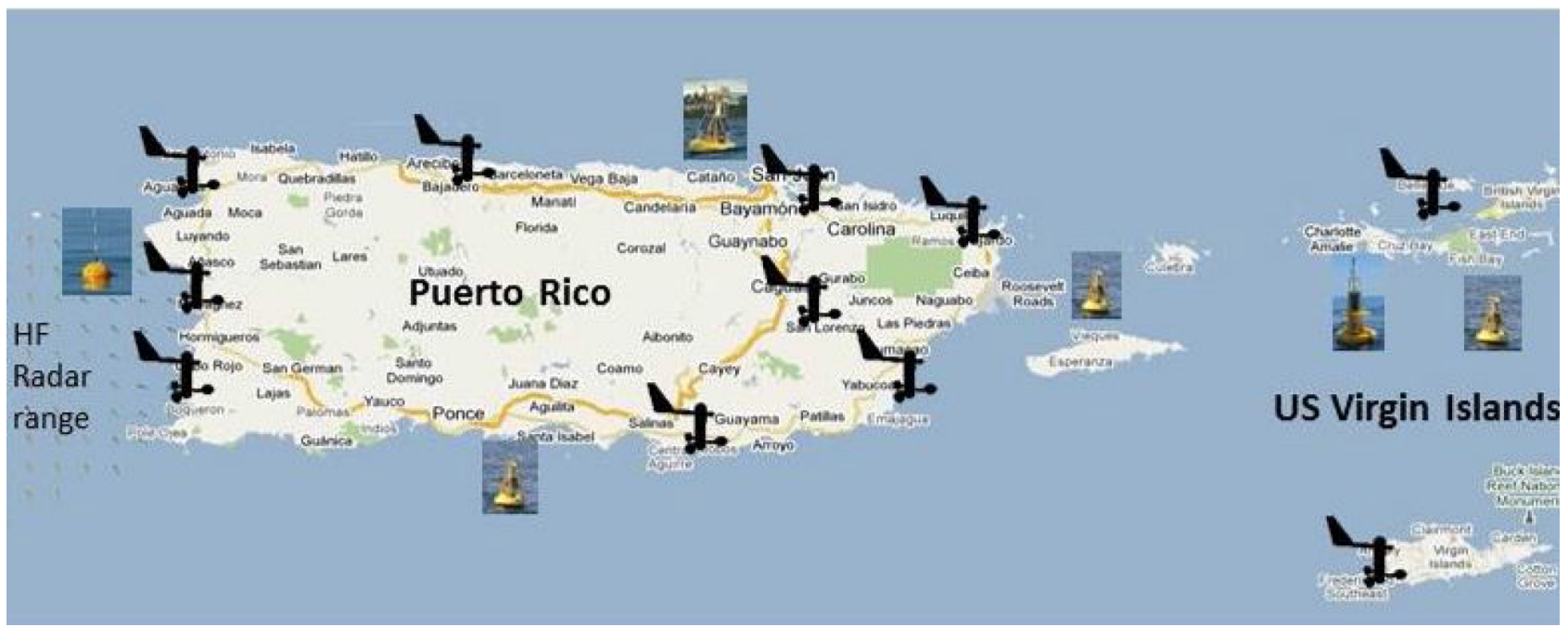

Fig. 7. CariCOOS weather stations and buoys, Puerto Rico and USVI. In the USVI the two anemometer symbols actually represent a total of six weather stations (map modified from CariCOOS web page, 2012).

\subsection{Science 100}

Even with the substantial scientific and educational contributions listed above, it is likely that the offering of "Science 100" will stand out as UVI's most lasting contribution to natural hazard preparedness and mitigation. Required of all freshmen during their first year at UVI, the course titled, "The Caribbean, The Natural World" and subtitled, "Hurricane, Earthquake, Tsunami and Volcano", is both successful and popular.

\subsubsection{Purpose and vision}

Science 100 was developed to improve college students' understanding and appreciation of the natural world, particularly of the Caribbean physical and biological environment, and to advance natural hazard awareness in all citizens. Fully interdisciplinary in its design it unifies the several sciences that explain the nature and effects of hurricanes, earthquakes, tsunamis and volcanoes. Its Caribbean focus makes it relevant to the student's real world.

\subsubsection{Immediate and complementary objectives}

At a public institution desirous of improving its student success and graduation rates, Science 100 unifies several approaches to freshmen-retention issues. Its pedagogical objectives typify what science college students are expected to advance if not master by the end of their first year - "Scientific Method", critical thinking, problem solving, skill in employing contemporary electronic media and tools, concepts of measuring, including S. I. (Système International) units. Important additional objectives are skill in laboratory procedures and in identifying and using institutional resources as well as team work and the employment of best practices in learning.

\subsubsection{Course design}

Science 100 is organized to build a framework of scientific skills, historical knowledge and computational competence around the attraction of the selected natural hazards, with which students are generally fascinated. At present the syllabus is organized as follows:

- Overview,

- Scientific Method,

- Physical Geography of the Caribbean,

- Caribbean Weather Patterns,

- Hurricanes,

- Volcanoes, Earthquakes, and Tsunamis,

- The Impacts of Natural Hazards on Marine and Terrestrial Ecosystems.

\subsubsection{Strategies}

Unique techniques designed and employed for the presentation of Science 100 include student co-learning, peer instructors, team teaching guest lecturers, and Campus Wide Experiences that include surveys of mangroves, reefs, succession forests and 100 million-year old geology.

\subsubsection{Outcomes}

Whether through student evaluations, assessment by external reviewers or anecdotally, Science 100 is perceived to have 
met most of its initial goals with much success. In the words of William Newell, Director of the Association for Interdisciplinary Studies, "If you could bottle the experience and sell it, you'd have all of higher education lined up outside your door ..." (Newell, 1997). The course has become a staple of the reformed curriculum experienced since its initial offering. As many as 8000 students on both campuses have experienced Science 100 since 1997. Among its most valuable outcomes is the introduction of many of these students to their local natural world, wilderness and vulnerability to coastal hazards with which they were previously unfamiliar.

\section{Observations for understanding, anticipating and mitigation}

\subsection{CariCOOS}

The Caribbean Coastal Ocean Observing System (CariCOOS) is the regional portion of the US Integrated Ocean Observing System, which in turn is part of a global approach to observing the ocean and the atmosphere to understand and predict weather, climate, as well as specific atmospheric or oceanic phenomena, such as tropical storms. CariCOOS is managed by the Caribbean Regional Association (CaRA) which is hosted by the University of Puerto Rico, Mayaguiez with the University of the Virgin Islands acting as one of its primary partners (CaRA, 2014). Government agencies and private entities that are deeply involved with marine, atmospheric or coastal resources are also collaborators in CaRA through a memorandum of agreement but can be clients as well. CaRA has gained recognition as a part of the national IOOS and, as such, has recruited funding from NOAA to build out CariCOOS's ocean and atmosphere assets. Among recently acquired assets are ocean data buoys and multi-functional weather stations, many of which are symbolized in Fig. 7. CariCOOS also collaborates with the observing systems of other regions to build the national system and to share assets and conduct observations useful to all partners whenever possible. CariCOOS databases, model outputs and other services are accessible through its webpage, www.caricoos.org/drupal.

\subsection{CariCOOS contributions to preparedness}

CariCOOS contributes to preparedness for coastal hazards in many ways and over several time frames. CariCOOS observations and publication of real-time winds, currents, seawater density, tides, water quality and other properties are immediately useful in operational oceanography. Fishers, port authorities, cruise ship facilitators, marine resource managers and tourism enterprises that are dependent on marine, atmospheric or coastal resources are all stakeholders that need real-time data to carry out their diverse responsibilities. For example, in order to do his job safely, a ship's captain guiding a huge vessel into port needs accurate real-time measurements that include currents, winds, and tides. Most immediately, search and rescue and other emergency responders need to access real-time current measurements to know where to look for persons washed adrift by storm surge or tsunami. But they also need computer simulations already tested, validated and archived in order to plan where best to deploy emergency assets in advance of the calamity. CariCOOS supports tsunami modeling using its in-house expertise and by persistently seeking to acquire the most precise bathymetric data possible, an essential factor in predicting the paths and behavior of tsunamis. CariCOOS databases and expertise have resulted in a recently completed USVI Storm Surge Atlas. This CariCOOS-sponsored project presents storm surge flooding scenarios for category 1 to 5 hurricanes approaching St. Croix, St. John, and St. Thomas from three angles of attack. These can be used for estimating what to expect from different hurricanes approaching from different directions (Benitez and Mercado, 2014). For products like this, VITEMA and the US National Weather Service are already fully engaged CariCOOS stakeholders.

\subsection{Long-term use of CariCOOS data and observations}

CariCOOS contributions to safety in the face of coastal hazards also extend to threats considered over longer time frames, such as the potential of a particular hurricane season, the possibility of future droughts or the likely impact of ocean warming and other consequences of global climate change. The same observations and measurements useful for computer modeling of circulation in bays and harbors and for anticipating storm surge are fundamental for diagnostic studies to understand events that have already occurred and also for longer-term climate change studies. For example, ocean temperature, on the surface and at depth, is among the most broadly essential of hydrographic measurements, relating to the energizing of tropical storms as well as to the density structure of the deep ocean that is significant in the acceleration or deceleration of climate change. Computer models developed from such data can allow emergency managers to anticipate how sea level change, for example, may imperil certain shoreline communities. They in turn can use their prerogative to advise community managers on the siting of facilities as well as to prepare already at-risk areas for inevitable problems.

After being subjected to quality-control processes and organized in user-friendly formats, CariCOOS observations are made available to various users in different configurations (tables, graphs, tables, animations, etc.) for immediate application but also archived for long-term use.

\section{Other contributors}

Other institutions, Territorial, regional national and international, have made significant contributions as well. For 
example, while US Government agencies have been the most reliable providers of support for many of the activities described in this paper, the Puerto Rico Seismic Network (PRSN) has deployed seismic sensor and Global Positioning System (GPS) networks in the USVI and has helped recruit funding for completion of USVI vertical datum for more precise elevation models. Using its own optimally located sensors and facilities, PRSN also facilitates the distribution of tsunami advisories and warnings from the National Tsunami Warning Center and contributes to earthquake event messages issued by the US Geological Service. Presently the fledgling Caribbean Tsunami Warning Program is accommodated at PRSN facilities (IOC, 2008).

\subsection{Federal Emergency Management Agency}

As explained above, the Federal Emergency Management Agency (FEMA) has contributed funds to support much of VITEMA's reorganization and other activities described above. In addition, it funds on-going tsunami awareness training to large numbers of USVI government and facility employees through the National Disaster Preparedness Training Center of the University of Hawaii.

\subsection{NWS and the Caribbean Tsunami Warning Program}

Especially throughout the hurricane season, VITEMA and other USVI government officials acquire much appreciation of the National Weather Service of the National Oceanic and Atmospheric Administration. NWS is the official conduit of information to the USVI on the progress of threatening tropical storms and also for corroboration of tsunami advisory messages. In response to persistent solicitations from many Caribbean nations in addition to Puerto Rico and the Virgin Islands, NWS has obtained NOAA support in initiating a Caribbean Tsunami Warning Program (CTWP) to explore the feasibility of a tsunami warning center for the region. The CTWP has been enthusiastically endorsed by USVI leaders from the Governor and the Congressional Delegate to the Director of VITEMA. NOAA maintains the already operative tsunami warning centers, such as the West Coast and Alaska Tsunami Warning Center that covers Puerto Rico and the USVI; its Deep-ocean Assessment and Reporting of Tsunami (DART) buoys are essential elements in tsunami warning. In addition NOAA supports a number other efforts described above. Through IOOS, NOAA is the primary funding source for the weather stations, observational buoys and other CariCOOS assets. Its National Tsunami Hazard Mitigation Program facilitated the early stages of USVI preparations for Tsunami-Ready status. Separately NOAA's National Data Buoy Center and National Water Level Observation Network provide information that contributes to every phase of preparedness for coastal hazards.

\subsection{International collaboration}

Through its Intergovernmental Oceanographic Commission for the Caribbean and Adjacent Regions, the Intergovernmental Oceanographic Commission has assembled regional human resources to promote hazard awareness throughout the region. On its behalf the first meeting of regional tsunami experts was convened on St. John, Virgin Islands in 1996. Since that time it has supported both ocean research and modeling workshops in the USVI. Its Intergovernmental Coordinating Group for the Tsunami and other Coastal Hazards Warning System for the Caribbean and Adjacent Regions (ICG-Caribe-EWS) was established in 2005 and continues to bring multinational experts and national officials together to build collaborative networks among the nations of the region to consider mitigations for future tsunami impacts It joins NWS and NTHMP in conducting the annual LANTEX tsunami exercise (IOC, 2013). In 2013 the ICG-Caribe-EWS chose the US Virgin Islands as the venue for its ninth (2014) session with VITEMA as its host.

\subsection{Private sector contributions to preparedness}

The private sector has made contributions to preparedness in the region through tsunami awareness workshops and educational activities. For example, Tropical Shipping and Caribbean-Central America Action, assisted by other private sector partners such as Baptist Hospital of Miami, have taken a series of Disaster Preparedness Workshops across international boundaries to inform many Caribbean communities.

\section{Conclusions}

In response to real provocations by tropical storms primarily but also by renewed awareness of the threat of earthquakes and tsunamis, the people, the Government and certain institutions in the USVI have developed attitudes, awareness, plans and procedures for preparing to mitigate assaults from these natural hazards. The official emergency management agency, VITEMA, has reinvented itself to be highly efficient to meet this challenge. Its eventual securing of Tsunami-Ready status for USVI communities will signal the achievement of yet another significant level of safety. UVI has followed all three mandates of its mission in contributing to USVI preparedness for natural hazard, (1) by teaching about natural hazards, most effectively with the offering of a course that 8000 students have now experienced, (2) by joining in research to better understand the natural hazards to which the region is susceptible, and (3) by sharing its knowledge and expertise with emergency managers and with the community as a whole. At the same time, CaRA/CariCOOS continues striving to improve the range and quality of its measurements and observations and makes its assets, databases, models and in-house expertise stand available and are already being used to assist in preparedness and mitigation for coastal hazards. 
These organizations, along with their private sector, governmental and international partners, lead the way towards optimal awareness and preparedness for natural hazards in the USVI.

Acknowledgements. The authors wish to thank Christa von Hillebrandt of the Caribbean Tsunami Warning Program, W. Douglas Wilson of Caribbean Wind and the Global Ocean Observing System, George Maul of Florida Institute of Technology, and Bradford Brown, formerly of NOAA's Southeast Fisheries Science Center, for the early and essential roles they have played in empowering the USVI to build its own campaign for security under the threat of natural hazard.

Edited by: J. Roger

Reviewed by: one anonymous referee

\section{References}

Barkan, R. and ten Brink, U.: Tsunami simulations of the 1867 Virgin Islands earthquake: Constraints on epicenter location and fault parameters, B. Seismol. Soc. Am., 100, 995-1009, 2010.

Benitez, J. and Mercado, A.: A storm surge atlas for the US Virgin Islands in support of emergency management, Poster: 6th General Assembly Caribbean Coastal Ocean Observing System, 13 March 2014.

Bram, J. and Hastings, J.: A long road to economic recovery for the U.S. Virgin Islands, http: //libertystreeteconomics.newyorkfed.org/2013/11/

a-long-road-to-economic-recovery-for-the-us-virgin-islands. html/, last access: 26 March 2014, Regional Analysis, Federal Reserve Bank of New York, 15 November 2013.

CaRA - Caribbean Regional Association: http://cara.uprm.edu/, last access: 30 March 2014.

CIA - Central Intelligence Agency: The World Factbook, https://www.cia.gov/library/publications/the-world-factbook/ geos/vq.html/, last access: 26 March 2014.

Climate Prediction Center: Multidecadal fluctuations in Atlantic hurricanes, NOAA Atlantic Hurricane Season Outlook Update, available at: http://www.cpc.ncep.noaa.gov/, last access: 26 March 2014, Press release issued 8 August 2013.

Department of Finance, Government of the US Virgin Islands: Exhibit I-1, General Fund Statement of Revenues, available at: http://www.usvi.org/oit/5yrplan/, last access: 31 July 2013, Government of the US Virgin Islands, 1999.

DHS - US Department of Homeland Security: Building BetterNew Building Code \& Power Upgrade, US Virgin Islands, https://www.llis.dhs.gov/content/, last access: 26 March 2014.

Dookhan, I.: A History of the Virgin Islands of the United States, Caribbean Universities Press - Bowker Publishing Company, St. Thomas, 1974.

EERI - Earthquake Engineering Research Institute: Building Better - case studies - US Virgin Islands, available at: http: //mitigation.eeri.org/files/resources-for-success/00090.pdf/, last access: 30 March 2014.
FEMA - Federal Emergency Management Agency: Region II: Report on mitigation activities in the US Virgin Islands, FEMA-DR-128-VI, available at: http://mitigation.eeri.org/files/ resources-for-success/00037.pdf/ (last access: 30 March 2014), October 2008.

Goldenberg, S. B., Landsea, C. W., Mestas-Nuñez, A. M., and Gray, W. M.: The recent increase in Atlantic hurricane activity: Causes and implications, Science, 293, 474-479, 2001.

Hamilton, A.: Royal Danish American Gazette, reporting on the hurricane of August 31, 1772 in St. Croix, October 3, available at: http://www.alexanderhamiltonexhibition.org/letters/10_ 03.html/ (last access: 29 March 2014), 1772.

IOC - Intergovernmental Oceanographic Commission: Establishment of a Caribbean Tsunami Warning Centre moves forward, http://www.ioc-unesco.org/index.php?option=com_content (last access: 26 March 2014), 2008.

IOC - Intergovernmental Oceanographic Commission: Exercise Caribe Wave/Lantex14, in: A Caribbean and Northwest Atlantic Tsunami Warning Exercise, 26 March 2014, Volume 1: Participant Handbook, IOC Technical Series No. 109, UNESCO, Paris, 2013.

IVI International: United States Seismic Zones Map, available at: http://www.ivi-intl.com/pdfs/IVIseismic_mapzones.pdf/, last access: 30 March 2014.

Lewis, E.: Planning: Ahead with NTHMP, National Tsunami Hazard Mitigation Program - Annual Meeting, 28-30 January 2014, US Geological Survey, Menlo Park, California, 2014.

Nealon, J. W. and Dillon, W. P.: Earthquake and Tsunamis in Puerto Rico and the U.S. Virgin Islands, US Department of the Interior, US Geological Survey Fact Sheet 141-00, available at: http://pubs.usgs.gov/fs/fs141-00/fs141-00.pdf/, last access: 30 March 2014, US Geological Survey, Reston, 2 pp., 2001.

Newell, W.: Report to the General Education Steering Committee, University of the Virgin Islands. Association for Interdisciplinary Studies, University of Miami in Ohio, 1997.

NDPTC - National Disaster Preparedness Training Center: Tsunami awareness AWR-217, https://ndptc.hawaii.edu/training/ catalog/1/, last access: 30 March 2014.

NWS - National Weather Service: TsunamiReady Guidelines, available at: http://www.tsunamiready.noaa.gov/guidelines.htm/, last access: 30 March 2014.

Sattler, D. N., Preston, A. J., Kaiser, C. F., Olivera, V. E., Valdez, J., and Schlueter, S.: Hurricane Georges: a cross-national study examining preparedness, resource loss, and psychological distress in the U.S. Virgin Islands, Puerto Rico, Dominican Republic, and the United States, http://www.ncbi.nlm.nih.gov/pubmed/ 12392221/, last access: 26 March 2014, J. Trauma Stress., 15, 339-50, 2002.

Smith, M. S. and Shepard, J. B.: Explosive submarine eruptions of Kick 'em Jenny volcano: preliminary investigations of the potential tsunami hazard in the Eastern Caribbean Region, in: Proceedings, Caribbean Conference on Natural Hazards: Volcanoes, Earthquakes, Windstorms, Floods, edited by: Ambeh, W. B., University of the West Indies, Mona Campus, 249-260, 1994. 
St. Croix Foundation: http://www.stxfoundation. org/wp/wp-content/uploads/2013/04/St.

-Croix-Foundation-USVI-Fact-Sheet.pdf/, last access: 29 March 2014.

van Housel, L.: An earthquake experience, Scribner's Monthly, 15, 662-672, 1878.

VITEMA: Annual Report 2011, 43 pp., available at: http://www. vitema.gov/assets/documents/2012/2011-annual-report.pdf/ (last access: 29 March 2014), 2011.

VITEMA: Governor de Jongh and VITEMA Director Lewis unveil V. I. Tsunami Evacuation Maps, available at: http:// www.vitema.gov/plan-prepare/tsumami/index.html/ (last access: 30 March 2014), 5 December 2013.
Wallace, J. A.: Montserrat's volcano erupts, Grenadian Connection.com, available at: http://grenadianconnection.com/Grenada/ ViewNews.asp?NID=3728\\&CID=15008\\&TC=1331 \\&EP= 452\\&yr=2006 \\&Cat=0000/ (last access: 20 March 2014), 21 May 2006.

Watlington, R. A.: An 1867-class tsunami: potential devastation in the United States Virgin Islands, in: Caribbean Tsunami Hazard, edited by: Mercado, A. and Liu, P., World Scientific Publishing Co., New Jersey, 255-267, 2006.

Zahibo, N., Pelinovsky, E., Yalciner, A. C., Kurkin, A., Koselkov, A., and Zaitsev, A.: The 1867 Virgin Island Tsunami, Nat. Hazards Earth Syst. Sci., 3, 367-376, doi:10.5194/nhess-3-3672003, 2003. 